\title{
Statistical bias correction on the climate model for el nino index prediction
}

\author{
Sri Nurdiati* ${ }^{1 *}$ Ardhasena Sopaheluwakan², Yoga Abdi Pratama $^{1}$, \\ Mohamad Khoirun Najib 1 \\ ${ }^{1}$ Department of Mathematics, Faculty of Mathematics and Natural Science, IPB University Bogor, Indonesia \\ ${ }^{2}$ Center for Applied Climate Services, Agency for Meteorology, Climatology, and Geophysics, Jakarta, Indonesia \\ nurdiati@apps.ipb.ac.id *
}

\section{Article Information}

Submitted May 05, 2021

Revised August, 122021

Accepted August 15, 2021

\section{Keywords}

Distribution Mapping;

El Nino-Southern Oscillation;

Linear Scaling;

Statistical Bias Correction;

Variance Scaling.

\begin{abstract}
El Nino can harm many sectors in Indonesia by reducing precipitation levels in some areas. The occurrence of El Nino can be estimated by observing the sea surface temperature in Nino 3.4 region. Therefore, an accurate model on sea surface temperature prediction in Nino 3.4 region is needed to optimize the estimation of the occurrence of El Nino, such as ECMWF. However, the prediction model released by ECMWF still consists of some systematic errors or biases. This research aims to correct these biases using statistical bias correction techniques and evaluate the prediction model before and after correction. The statistical bias correction uses linear scaling, variance scaling, and distribution mapping techniques. The results show that statistical bias correction can reduce the prediction model bias. Also, the distribution mapping and variance scaling are more accurate than the linear scaling technique. Distribution mapping has better RMSE in December-March, and variance scaling has better RMSE in April-June also in October and November. However, in July-September, prediction from ECMWF has better RMSE. The application of statistical bias correction techniques has the highest refinement in January-March at the first lead time and in April at the fifth until the seventh lead time.
\end{abstract}

\section{INTRODUCTION}

El Nino is an extreme climatic phenomenon due to climatic elements (such as sea surface temperatures) higher than normal conditions for a certain period. During El Nino, sea surface temperatures are warmer than normal conditions in the central Pacific and increasing precipitation levels in Peru, Chile, and Ecuador. Conversely, precipitation levels in Indonesia, Papua New Guinea, and surrounding countries have decreased from normal conditions (Philander, 1983).The El Nino decrease food production (rice and secondary crops) in Indonesia by 3.06 percent or around 1.79 million tons during El Nino events (Irawan, 2006). This is an earnest problem for farmers in Indonesia, so an effort is needed to minimize the impact of the El Nino phenomenon, such as predicting El Nino events using sea surface temperatures. Predicting sea surface temperatures has been done by many organizations or research institutions that observe climate and weather, one of which is the European Centre for Medium-Range Weather Forecasts (ECMWF). ECMWF is a research institute and operational service that produces numerical weather predictions. However, sea surface temperature prediction from ECMWF products still has biases compared to its observational data. These biases can significantly impact seasonal forecasts and future climate predictions (Shonk et al., 2019). Thus, a statistical bias correction method is needed to minimize the biases (Najib \& Nurdiati, 2021). 
Experts have developed many statistical bias correction techniques, such as distribution mapping or quantile mapping (Alidoost et al., 2021; Enayati et al., 2021; Piani et al., 2010), linear scaling (Bahari et al., 2021; Lenderink et al., 2007; Rahimi et al., 2021), and variance scaling (Barbosa et al., 2021; Chen et al., 2011; Singh et al., 2021). For example, in a previous research, Misnawati et al. (2018) tested linear scaling, distribution mapping, multiple linear regression, and power regression to correct CHIRPS data based on precipitation data from the observational station in Central Java Province, Indonesia. The results conclude that multiple linear and power regression gives better performance in describing observational precipitation. Furthermore, Lealdi et al. (2018) used quantile mapping to see the relationship between the ECMWF data and the observational station in Bali Island from 1996-2015.

This research used several bias correction techniques (such as distribution mapping, linear scaling, and variance scaling) to minimize the bias of the SST prediction model in the Nino 3.4 region derived from ECMWF products. Nino 3.4 region is selected because this region represents the average equatorial sea surface temperature across the Pacific, from the dateline to the South America coast (Trenberth, 2020). Also, Nino 3.4 region is widely used by researchers to observe the El Nino phenomenon (Nurdiati et al., 2021).

\section{METHODS}

Authors used Optimum Interpolation Sea Surface Temperature (OISST) as an observation model and European Center for Medium-Range Weather Forecasts (ECMWF) as forecasting data from 1983 to 2018 in Network Common Data Form (NetCDF) format. Authors used OISST data because it is a combination of data observations from different platforms and is used to determine the Nino index (www.cpc.ncep.noaa.gov/data/indices/). This data is used as the basis for correcting the ECMWF data. The obtained OISST data is a global sea surface temperature data with a spatial resolution of $0.25^{\circ} \times 0.25^{\circ}$ and daily temporal resolution. This data has dimensions of $1440 \times 720 \times 365$ or 366 (longitude $\times$ latitude $\times$ day). Otherwise, the obtained ECMWF data is SST prediction data in the Nino 3.4 region with a spatial resolution of $0.25^{\circ} \times 0.25^{\circ}$ and daily temporal resolution. This data has dimensions of $205 \times 45 \times 25 \times$ 216 (longitude $\times$ latitude $\times$ ensemble $\times$ lead time). OISST data extracted in the Nino 3.4 region from 1983-2018 in the Nino 3.4. Otherwise, ECMWF data is predictive data that predicting sea surface temperature in the next seven months and collected from 1983-2018. Meaning, ECMWF data in January 1983 cover SST prediction for January-July 1983 and so on. The SST prediction for a month derived from the same month is called lead 1, while the SST prediction for a month derived from the previous month is called lead 2, and so on until lead 7. Data is partitioned into two sets for both data types, i.e., 1983-2012 as training data and 2013-2018 as testing data.

Statistical bias correction is used to correct the bias from the prediction model based on the observation model. Many statistical bias correction techniques have been developed by experts, such as distribution mapping or quantile mapping, linear scaling, and variance scaling. Distribution mapping corrects the bias of the ECMWF model based on the observation model by establishing a transfer function $y=f(x)$. The transfer function connects the cumulative distribution function (CDF) of the ECMWF and observation models (Piani et al., 2010) and given by 


$$
C D F_{\text {OISST }}(f(x))=C D F_{E C M W F}(x)
$$

where $C D F_{\text {OISST }}(f(x))$ and $C D F_{E C M W F}(x)$ are CDF values of the observation and prediction models, respectively (Nurdiati et al., 2019). Misnawati et al. (2018) said that the first step in distribution mapping identifies the distribution and probability density function of both data (prediction and observation). The second step is computing the cumulative distribution by integrating the probability density function. The third step is creating a transfer function between the prediction and observation model cumulative distribution. After that, the transfer function was used to correct the prediction CDF model, and the corrected PDF model is the derivative of the corrected CDF model. An illustration of the bias correction process using distribution mapping is shown in Figure 1.
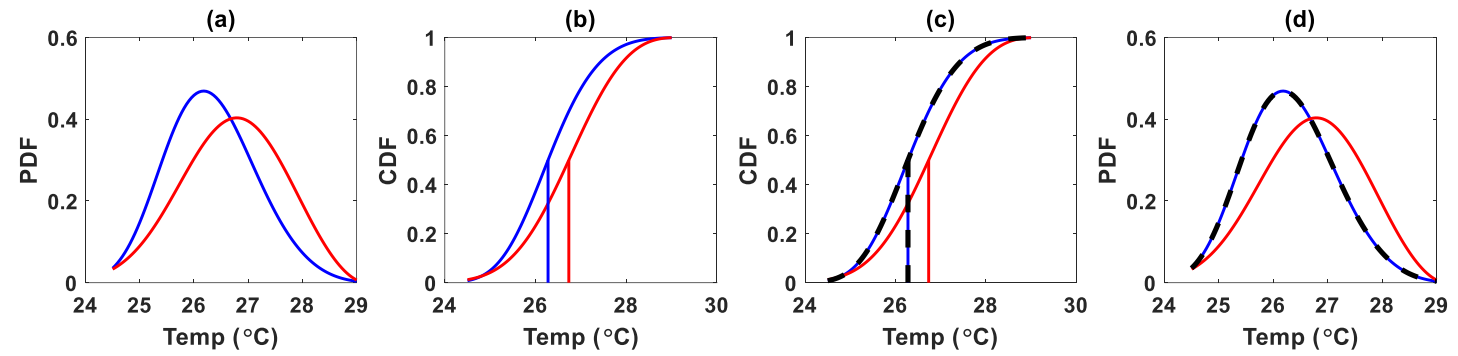

-OISST —ECMWF - - - Corrected ECMWF

Figure 1. Illustration process of the distribution mapping technique: (a) identifying distribution, (b) computing cumulative distribution function (CDF), (c) creating a transfer function and calculating the corrected CDF model, and (d) calculating the corrected PDF model.

For the second method, linear scaling adjusts the prediction model based on the difference between the prediction model and the observation model on average (Lenderink et al., 2007), given by

$$
T_{C O R}=T_{E C M W F}+\left(\bar{T}_{\text {OISST }}-\bar{T}_{E C M W F}\right)
$$

where $T_{C O R}$ and $T_{E C M W F}$ are the ECMWF model after and before corrected, respectively, while $\bar{T}_{\text {OISST }}$ and $\bar{T}_{E C M W F}$ are the average of the OISST and ECMWF models, respectively. An illustration of the bias correction process using linear scaling is shown in Figure 2.

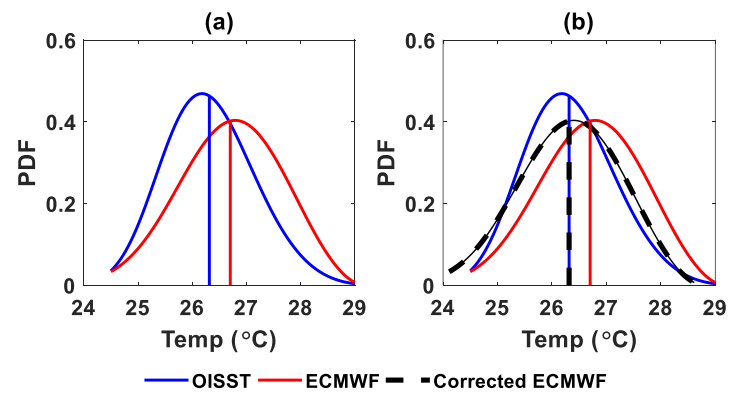

Figure 2. Illustration of the bias correction process using linear scaling: (a) identifying distribution,

(b) shifting the prediction data using equation (2).

Otherwise, the variance scaling method corrects the prediction model by adjusting the mean and variance values (Chen et al., 2011). A variance scaling is a three steps bias correction method (Teutschbein \& Seibert, 2012; Yamamoto et al., 2021). The first step is correcting $T_{E C M W F}$ using linear scaling in equation (2). The result denotes using $T_{E C M W F}^{*}$ and shift the average to zero by

$$
T_{E C M W F}^{* *}=T_{E C M W F}^{*}-\mu_{E C M W F}^{*}
$$


where $\mu_{E C M W F}^{*}$ is the mean of $T_{E C M W F}^{*}$. In the second step, the standard deviation of $T_{E C M W F}^{* * *}$ is corrected using

$$
T_{E C M W F}^{* * *}=T_{E C M W F}^{* * *} \times \frac{\sigma_{O I S S T}}{\sigma_{E C M W F}^{* *}}
$$

where $\sigma_{\text {OISST }}$ and $\sigma_{E C M W F}^{* *}$ are the standard deviation of $T_{\text {OISST }}$ and $T_{E C M W F}^{* *}$, respectively. The final step, restore the average of the ECMWF model using

$$
T_{C O R}=T_{E C M W F}^{* * *}+\mu_{E C M W F}^{*}
$$

where $T_{C O R}$ is the corrected ECMWF and $\mu_{E C M W F}^{*}$ is the mean of $T_{E C M W F}^{*}$. An illustration of the bias correction process using linear scaling is shown in Figure 3.
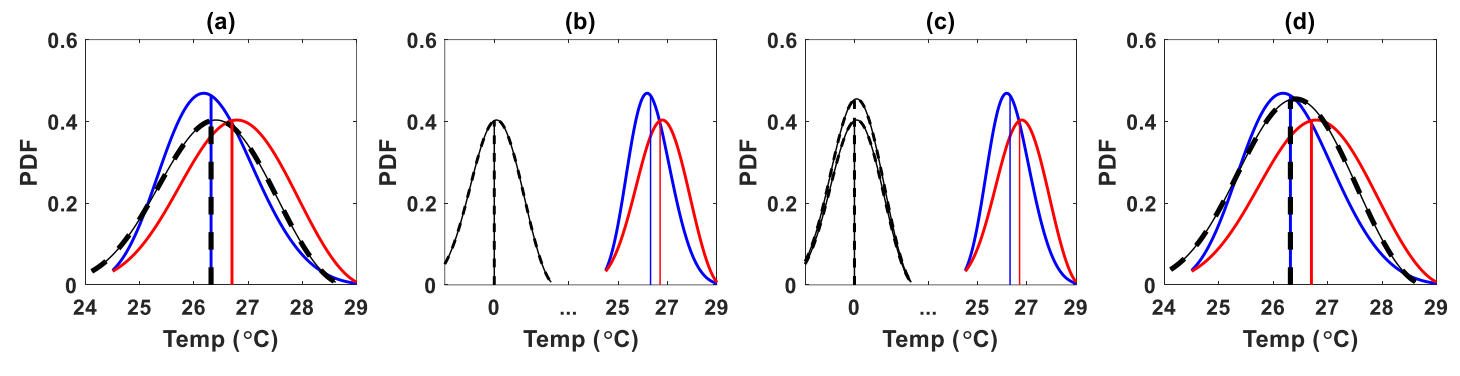

Figure 3. Illustration of the bias correction process using variance scaling: (a) the result of linear scaling $T_{E C M W F}^{*}$, (b) shifting to zero mean $T_{E C M W F}^{* *}$, (c) scaling the standard deviation using equation (4)

$$
T_{E C M W F}^{* * * *} \text {, and (d) shifting to original mean } T_{C O R} \text {. }
$$

The three statistical bias correction techniques require a parametric distribution for processing. In this research, the prediction and observation model distribution is fitted using several parametric distributions, such as beta (Johnson et al., 1995), Birnbaum-Saunders (Johnson et al., 1995), exponential (Johnson \& Wichern, 2007), extreme value (De Haan \& Ferreira, 2006), gamma (Hogg \& Craig, 1978), generalized extreme value (De Haan \& Ferreira, 2006), logistic (Sarkar \& Balakrishnan, 1994), log-logistic (Bennett, 1983), lognormal (Johnson et al., 1995), Nakagami (Mitra et al., 2012), normal (Hogg \& Craig, 1978), Rayleigh (Siddiqui, 1964), Rician (Talukdar \& Lawing, 1991), t location-scale (Mayer, 1987), and Weibull (Papoulis \& Pillai, 2002) distribution. The distribution is selected based on several parameters such as Negative of the Log-Likelihood (NLogL), Bayesian Information Criterion (BIC), Akaike Information Criterion (AIC) dan AIC with a correction for finite sample sizes (AICc) (Liddle, 2007).

The prediction models in testing data before and after corrected are evaluated against the observation model using Root Mean Square Error (RMSE), as follow

$$
R M S E=\sqrt{\frac{1}{N} \sum_{i=1}^{N}\left(\hat{f}_{i}-f_{i}\right)^{2}}
$$

where $\mathrm{N}$ is the sample size of data, $\hat{f}_{i}$ and $f_{i}$ represent the prediction and observation model (Zhang \& Singh, 2007).

\section{RESULTS AND DISCUSSION}

General descriptions between the prediction and observation models are used to identify characteristics among the data, such as comparisons of distribution's shape, skewness, range, etc. For example, using the violin plot, Figure 4 shows three general relationships between the prediction and observation models represented by January, April, and August. Violin plot 
combines box plot and data distribution function on both sides (Hintze \& Nelson, 1998). We used MATLAB for both computation and data analysis.
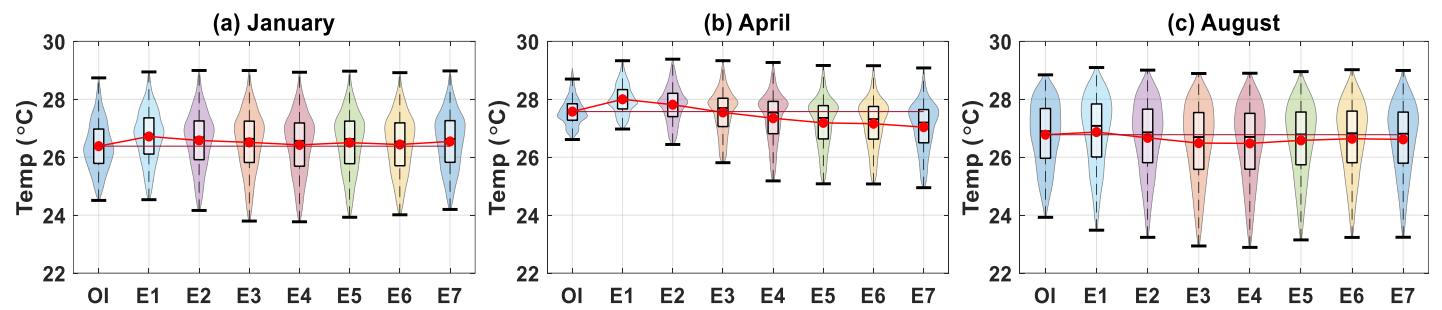

Figure 4. Violin plot of the prediction (E1-E7, ECMWF at lead time 1-7 months) and observation

(OI, OISST) models in (a) January, (b) April, and (c) August

There are three general distribution relationships between the OISST observation model and the ECMWF prediction model. First, Figure 4(a) shows the mean of the prediction model higher (or the same at the longer lead times) than the observation model (generally overestimated). Second, the observation model has positive skewness from the distribution's shape, which means that the right-hand tail will be longer than the left-hand tail. Otherwise, the prediction model has a nearly symmetric distribution. Finally, besides January, the month with this relationship is in February, March, and December.

Furthermore, Figure 4(b) shows the mean of the prediction model higher at the shorter lead times but lower at the longer lead times than the observation model. The observation model has a nearly symmetric distribution from the distribution's shape. The prediction model has negative skewness, which means that the right-hand tail will be shorter than the left-hand tail. Besides April, the month with this relationship is in May, June, October, and November. Last, Figure 4(c) shows the mean of the prediction model higher at the first lead time but lower at another lead time than the observation model (generally underestimated). The observation and prediction models have negative skewness from the distribution's shape, which means that the right-hand tail will be shorter than the left-hand tail. Besides August, the month that has this relationship is in July and September.

The high variance implies the low precision of the prediction. Conversely, if the variation is too slight, the prediction model cannot reach the extreme value of the observation. Thus, a statistical bias correction is needed to correct the prediction model by identifying the relationship against the observation model. The three statistical bias correction techniques require a parametric distribution for processing. Using parametric distributions mentioned above. Table 1 shows the results of the fitting distribution process of the prediction and observation model training data in January at the first lead time after sorting by the goodness of fit parameter.

Table 1. The first three results of the fitting distribution process of the prediction and observation model training data in January

\begin{tabular}{|c|c|c|c|c|c|}
\hline \multicolumn{3}{|c|}{ Lead time 1 prediction model } & \multicolumn{3}{|c|}{ Observation model } \\
\hline Distribution & Parameter & Goodness of fits & Distribution & Parameter & Goodness of fits \\
\hline Generalized & $k=-0.339$ & NLogL: 1031 & Generalized & $k=-0.224$ & NLogL: 9914 \\
\hline Extreme & $\sigma=0.9108$ & BIC: 2064 & Extreme Value & $\sigma=0.8021$ & BIC: 1985 \\
\hline Value & $\mu=26.426$ & AIC: 2062 & & $\mu=26.064$ & AIC: 1983 \\
\hline \multirow[t]{2}{*}{ Normal } & $\mu=26.715$ & NLogL: 1038 & Birnbaum- & $\beta=26.367$ & NLogL: 9967 \\
\hline & $\sigma=0.8856$ & $\begin{array}{l}\text { BIC: } 2078 \\
\text { AIC: } 2076\end{array}$ & Saunders & $\gamma=0.0316$ & $\begin{array}{l}\text { BIC: } 1995 \\
\text { AIC: } 1994\end{array}$ \\
\hline \multirow[t]{3}{*}{ Rician } & $s=26.7012$ & NLogL: 1038 & Log-normal & $\mu=3.2721$ & NLogL: 9968 \\
\hline & $\sigma=0.8858$ & BIC: 2078 & & $\sigma=0.0316$ & BIC: 1995 \\
\hline & & AIC: 2076 & & & AIC: 1994 \\
\hline
\end{tabular}


As mentioned above, the prediction and observation model distributions are selected based on NLogL, BIC, and AIC. Table 1 shows that generalized extreme value distribution is the fittest parametric distribution for the prediction model at lead time 1 and the observation model. Generalized extreme value distribution is a family of continuous probability distributions developed within extreme value theory to combine the Gumbel, Fréchet, and Weibull families. The GEV distribution is the only possible limit distribution of properly normalized maxima of a sequence of independent and identically distributed random variables (De Haan \& Ferreira, 2006). This process is repeated for the observation and prediction models at the first until the seventh lead times.

The statistical bias correction process is divided into two stages, namely the training and testing stages. The training prediction model will be corrected in the training stage based on the training observation model using the distribution mapping, linear scaling, and variance scaling techniques mentioned above. This stage produces a transfer value from each method. Furthermore, the transfer value is used to correct the testing prediction model in the testing stages.

The results of the distribution mapping, linear scaling, and variance scaling techniques are used to correct the ECMWF prediction models in 2013-2018. For example, statistical bias correction for the ECMWF prediction models in January 2013-2018 and their comparison to the OISST observation model are shown in Figure 5. The statistical bias correction method can correct the prediction model at lead time 1, i.e., the mean and variance of the corrected testing prediction model are closer to the observation model than the ECMWF prediction model. Unlike distribution mapping or variance scaling, linear scaling does not refine the variance of the prediction model but only refines the mean by shifting the distribution. All three statistical bias correction techniques can refine the prediction model on average. The linear scaling method is the fittest model in January at the first lead time by a distribution range. Refinement to the mean is also seen in lead times 2 and 3, but the fittest models are given by the distribution mapping and variance scaling, respectively. Otherwise, in the 4th7th lead time, refinements to the mean are not seen. The only improvement occurred in the variance of the prediction models, which is closer to the variance of the observation model. The distribution mapping technique gives the fittest models in January at the 4th-7th lead time.

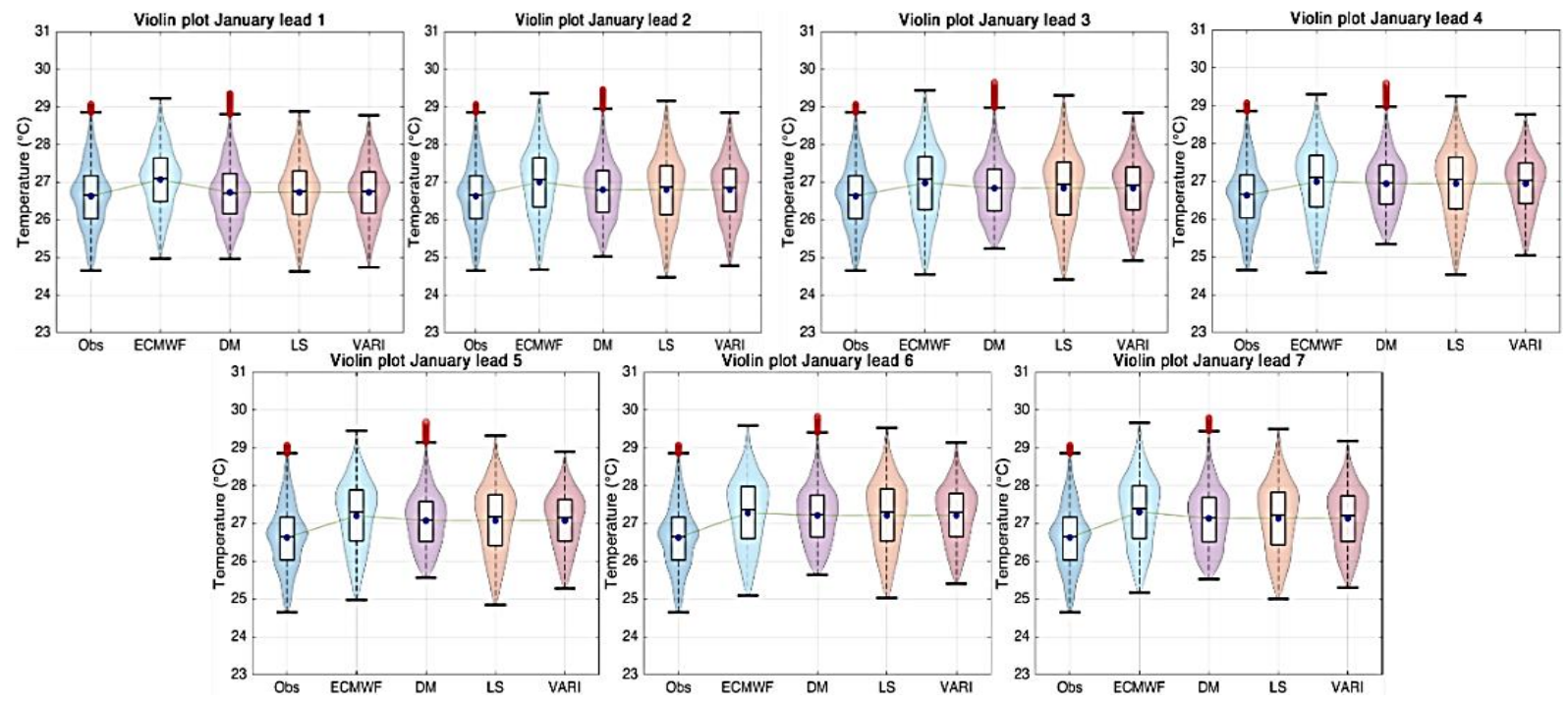

Figure 5. The results of statistical bias correction for the ECMWF prediction models in January 20132018 and their comparison to the OISST observation model. 
The testing processes are repeated for each month and lead time. However, the results are not analyzed one by one. The statistical bias correction technique is said to be successfully correct the prediction model if the RMSE value of the corrected prediction model is lower than the RMSE value of the ECMWF model before correction. The fittest model, RMSE value of the most suitable model, and the amount of RMSE refinement from the ECMWF prediction model for each month and lead time are given by the heatmap plot in Figure 6 .

Figure 6(a) shows that the distribution mapping and variance scaling techniques are more fit than the linear scaling technique. Distribution mapping has better RMSE in December-March, and variance scaling has better RMSE in April-June also in October and November. However, in July-September, the prediction from ECMWF has better RMSE, which means that statistical bias correction techniques are unsuccessfully corrected the prediction model in these months. Furthermore, Figure 6(b) shows that the prediction model has high accuracy in the first until third lead time for each month. In the lead time of more than three months, the prediction model just accurate to predict the SST over Nino 3.4 region in March-June. Generally, Based on Figure 6(c), the application of statistical bias correction techniques has the highest refinement in January-March at the first lead time and also in April at the fifth until the seventh lead time. Moreover, the maximum refinement of distribution mapping is 0.34 , better than linear scaling and variance scaling with 0.32 and 0.30 .

(a)

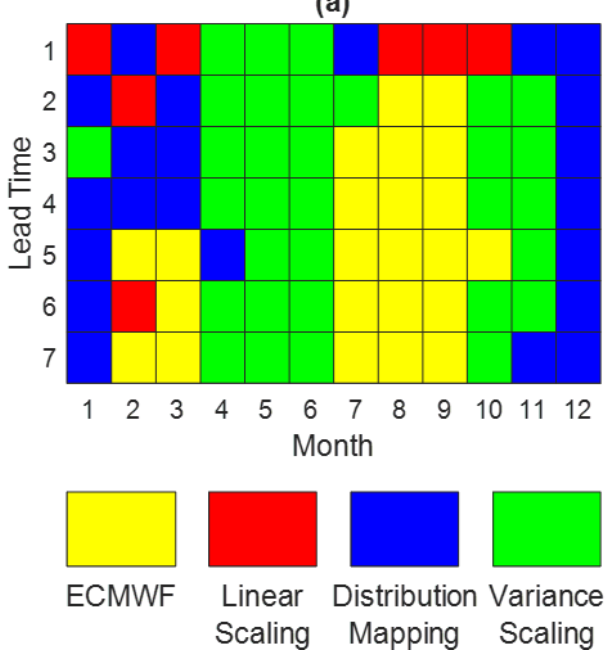

(b)

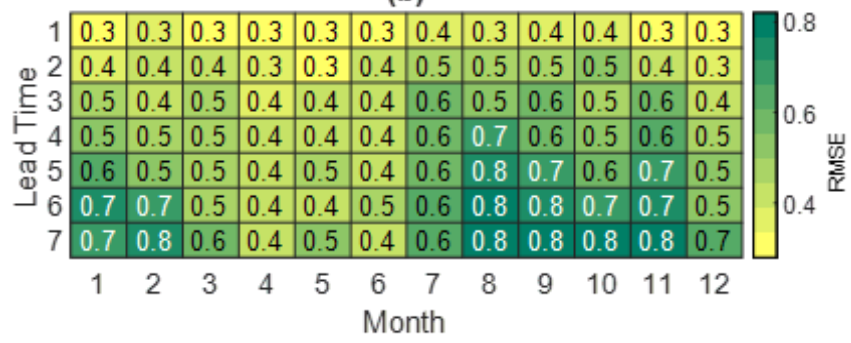

(c)

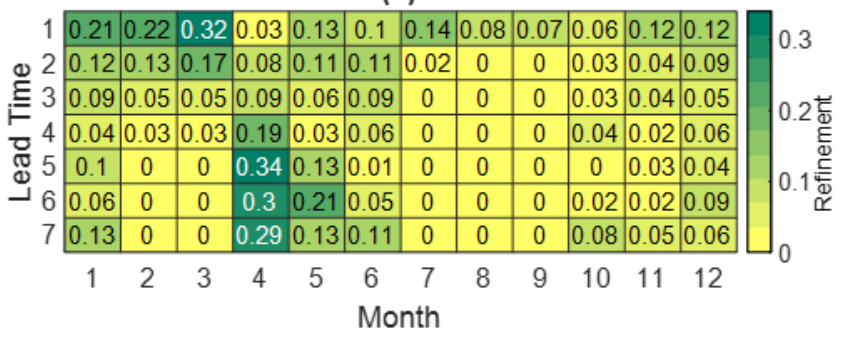

Figure 6. (a) the fittest model, (b) the RMSE value of the fittest model, and (c) the amount of RMSE refinement from the ECMWF prediction model for each month and lead time.

\section{CONCLUSIONS}

The research results show that statistical bias correction using linear scaling, variance scaling and distribution mapping can reduce the prediction model bias. In the fitting process, authors found that the fittest distribution of most months and lead time of the data is the GEV distribution. Based on the RMSE value, the distribution mapping and variance scaling are more accurate than the linear scaling technique. Distribution mapping has RMSE in December-March, while variance scaling better in April-June and October-November. However, in July-September, prediction from ECMWF has better RMSE. Moreover, statistical bias correction techniques have the highest refinement in January-March at the first 
lead time and in April at the fifth until the seventh lead time. Generally, distribution mapping is better than variance scaling or linear scaling based on the maximum refinement value.

\section{AUTHOR CONTRIBUTIONS STATEMENT}

$\mathrm{SN}$ is the main drafter. AS, YAP, and MKN helped process articles, search for relevant literature, and find places to publish articles.

\section{REFERENCES}

Alidoost, F., Stein, A., Su, Z., \& Sharifi, A. (2021). Multivariate copula quantile mapping for bias correction of reanalysis air temperature data. Journal of Spatial Science, 66(2), 299-315.

Bahari, N. I. S., Muharam, F. M., Zulkafli, Z., Mazlan, N., \& Husin, N. A. (2021). Modified linear scaling and quantile mapping mean bias correction of MODIS land surface temperature for surface air temperature estimation for the lowland areas of peninsular malaysia. Remote Sensing, 13(13), 2589.

Barbosa, C. C., Calijuri, M. do C., dos Santos, A. C. A., Ladwig, R., de Oliveira, L. F. A., \& Buarque, A. C. S. (2021). Future projections of water level and thermal regime changes of a multipurpose subtropical reservoir (Sao Paulo, Brazil). Science of the Total Environment, 770 .

Bennett, S. (1983). Log-logistic regression models for survival data. Applied Statistics, 32(2), $165-171$.

Chen, J., Brissette, F. P., \& Leconte, R. (2011). Uncertainty of downscaling method in quantifying the impact of climate change on hydrology. Journal of Hydrology, 401(34), 190-202.

De Haan, L., \& Ferreira, A. (2006). Extreme value theory: An introduction. In Springer Series in Operations Research and Financial Engineering. Springer.

Enayati, M., Bozorg-Haddad, O., Bazrafshan, J., Hejabi, S., \& Chu, X. (2021). Bias correction capabilities of quantile mapping methods for rainfall and temperature variables. Journal of Water and Climate Change, 12(2), 401-419.

Hintze, J. L., \& Nelson, R. D. (1998). Violin plots: A box plot-density trace synergism. American Statistician, 52(2), 181-184.

Hogg, R. V., \& Craig, A. T. (1978). Introduction to mathematical statistics. MacMillan.

Irawan, B. (2006). Fenomena anomali iklim el nino dan la nina: Kecenderungan jangka panjang dan pengaruhnya terhadap produksi pangan. Forum Penelitian Agro Ekonomi, $24(1), 28-45$.

Johnson, N. L., Kotz, S., \& Balakrishnan, N. (1995). Continuous univariate distributions (2nd ed.). John Wiley.

Johnson, R. A., \& Wichern, D. W. (2007). Applied multivariate statistical analysis. Pearson Prentice Hall. 
Lealdi, D., Nurdiati, S., \& Sopaheluwakan, A. (2018). Statistical bias correction modelling for seasonal rainfall forecast for the case of Bali Island. Journal of Physics: Conference Series, 1008(1), 012018.

Lenderink, G., Buishand, A., \& Van Deursen, W. (2007). Estimates of future discharges of the river rhine using two scenario methodologies: Direct versus delta approach. Hydrology and Earth System Sciences, 11(3), 1145-1159.

Liddle, A. R. (2007). Information criteria for astrophysical model selection. Monthly Notices of the Royal Astronomical Society: Letters, 377(1), L74-L78.

Mayer, J. (1987). Two-moment decision models and expected utility maximization. American Economic Review, 77, 421-430.

Misnawati, Boer, R., June, T., \& Faqih, A. (2018). Perbandingan metodologi koreksi bias data curah hujan CHIRPS. LIMNOTEK - Perairan Darat Tropis Di Indonesia, 25(1), 18-29.

Mitra, R., Mishra, A. K., \& Choubisa, T. (2012). Maximum likelihood estimate of parameters of nakagami-m distribution. Proceedings of the 2012 International Conference on Communications, Devices and Intelligent Systems, CODIS 2012, 9-12.

Najib, M. K., \& Nurdiati, S. (2021). Koreksi bias statistik pada data prediksi suhu permukaan air laut di wilayah Indian ocean dipole barat dan timur. Jambura Geoscience Review, $3(1), 9-17$.

Nurdiati, S., Khatizah, E., Najib, M. K., \& Fatmawati, L. L. (2021). El nino index prediction model using quantile mapping approach on sea surface temperature data. Desimal: Jurnal Matematika, 4(1), 79-92.

Nurdiati, S., Sopaheluwakan, A., \& Najib, M. K. (2019). Statistical bias correction for predictions of Indian ocean dipole index with quantile mapping approach. International MIPAnet Conference on Science and Mathematics (IMC-SciMath), Medan.

Papoulis, A. P., \& Pillai, S. U. (2002). Probability, random variables, and stochastic processes (4th ed.). McGraw-Hill.

Philander, S. G. H. (1983). El Nino southern oscillation phenomena. Nature, 302(5906), 295301.

Piani, C., Haerter, J. O., \& Coppola, E. (2010). Statistical bias correction for daily precipitation in regional climate models over Europe. Theoretical and Applied Climatology, 99(1-2), 187-192.

Rahimi, R., Tavakol-Davani, H., \& Nasseri, M. (2021). An uncertainty-based regional comparative analysis on the performance of different bias correction methods in statistical downscaling of precipitation. Water Resources Management, 35(8), 25032518.

Sarkar, S. K., \& Balakrishnan, N. (1994). Handbook of the logistic distribution. Marcel Dekker. 
Shonk, J. K. P., Demissie, T. D., \& Toniazzo, T. (2019). A double ITCZ phenomenology of wind errors in the equatorial atlantic in seasonal forecasts with ECMWF models. Atmospheric Chemistry and Physics, 19(17), 11383-11399.

Siddiqui, M. M. (1964). Statistical inference for rayleigh distributions. Journal of Research of the National Bureau of Standards, Section D: Radio Science, 68D(9), 1005.

Singh, S., Mall, R. K., Dadich, J., Verma, S., Singh, J. V., \& Gupta, A. (2021). Evaluation of CORDEX-south asia regional climate models for heat wave simulations over india. Atmospheric Research, 248, 105228.

Talukdar, K. K., \& Lawing, W. D. (1991). Estimation of the parameters of the rice distribution. Journal of the Acoustical Society of America, 89(3), 1193-1197.

Teutschbein, C., \& Seibert, J. (2012). Bias correction of regional climate model simulations for hydrological climate-change impact studies: Review and evaluation of different methods. Journal of Hydrology, 456-457, 12-29.

Trenberth, K. (2020). The climate data guide: Nino SST indices (Nino 1+ 2, 3, 3.4, 4; ONI and TNI). Climate Data Guide; UCAR: Boulder, CO, USA.

Yamamoto, K., Sayama, T., \& Apip. (2021). Impact of climate change on flood inundation in a tropical river basin in Indonesia. Progress in Earth and Planetary Science, 8(1), 1-15.

Zhang, L., \& Singh, V. P. (2007). Gumbel-hougaard copula for trivariate rainfall frequency analysis. Journal of Hydrologic Engineering, 12(4), 409-419. 